\title{
Identifying Potential to Promote the NOS in Elementary Science Teaching Packages
}

\author{
Konstantinos Karampelas \\ University of the Aegean, \\ Rhodes, Greece
}

\begin{abstract}
This paper aims to identify whether teaching the Nature of science is promoted in the teaching package of Greek Elementary School. Literature has justified that the nature of science is an important aspect of science teaching, which helps learners acquire a better understanding of science and its branches. Additionally, literature has suggested that for the nature of science to be taught, it is important for learners to get involved in activities, which emphasize on the epistemological aspect of science, the explanatory aspect of science, and the data issues aspect. However, research claims that the nature of science has not been effectively implemented in actual science teaching in many countries. A significant reason for that is the lack of the appropriate teaching material, such as teaching package. Through a qualitative approach with the help of the directed content analysis, this paper examines whether the science teaching package of Greek Elementary Curriculum emphasizes on the three basic aspects. The findings show that there is little emphasis.
\end{abstract}

Keywords: nature of science; elementary school; teaching package; content analysis.

\section{Introduction}

Science teaching aims at the promotion of scientific literacy, which according to Organisation for Economic Cooperation and Development -OECD (2006), focuses on the development of four interrelated features for individuals. The first is scientific knowledge construction and the use of that knowledge in order to state questions, gain new knowledge, explain phenomena, and to draw evidence-based conclusions about issues relevant to science. The second is about understanding the characteristic features of science as form of human knowledge and inquiry. The third is the knowing how science and technology influences our material, intellectual, and cultural environments. The fourth is about being willing to engage in science-related issues and with the ideas of science, which is a characteristic of as constructive, concerned, and reflective citizen. As concluded from the above and underlined by the current approaches, 
there is a need for science teaching to emphasize on skills, attitudes, and practices as well as the nature of science (NOS). The NOS addresses to the general precision of the field of science, its characteristics, the foundation of scientific work as human activity, and the influences and interaction of science with the wider community (Clough, 2007). The advantage of this approach is the familiarization of learners with the scientific process, the potential of scientific knowledge and the identification of topics for research, the clarification of the boundaries between science and other fields of study, and finally, the appreciation of science to the development and progress of the community (Driver et al., 1996; Bell, 2008; Roblin et al., 2017).

Teaching the NOS is often confused with teaching science process, which is certainly a major parameter of it but not the only one. The others are the construction of concepts relevant to the characteristics of science along with core disciplinary ideas, along with cross-cutting context skills. This approach helps learners to get deeper their understanding of science as a system in order to explain the Natural world through a series of practices and research accumulative knowledge.

Overall, in trying to be precise about what the NOS is and how it should be involved in science teaching, research points out that the NOS mainly has to do with: 1) body of knowledge, 2) methodological process, and 3) way of knowing. This set includes the basic characteristics of scientific knowledge, process, and values. Even though different groups of researchers may approach the NOS differently and point out different traits, most of them agree that the set of these three dimensions is perhaps the essence of the point (Lederman, 2007).

Driver et al. (1996) identified the five basic principles or the so-called "arguments" that teaching the NOS can help learners appreciate. The first is utilitarian, as the NOS can help learners understand the utility of scientific concepts and the contribution to technology in everyday life. The second is democratic, as teaching the NOS can provide better grounds for effective decision making in what concerns scientific and non-scientific matters. The third one is cultural, as thanks to the NOS, learners can deepen their understanding about the interaction between science and cultural matters. The fourth one is moral, since science topics are often linked to moral aspects and limitation that can be better understood thanks to teaching the NOS. Finally, the fifth one is science learning, which can be assisted by effective learning of the NOS. Therefore, it is crucial for these elements-arguments to be involved or negotiated in science teaching.

In relation to the above, Lederman (2007) pointed out basic points that learners need to conceive in order to achieve a deep understanding of the NOS. Most of these points are linked to misconceptions held by learners about science and scientific knowledge in general (Driver et al., 1996).

First, learners need to understand the difference between observation and inference. The former is about describing phenomena, which is based usually on senses. The latter goes beyond that. 
Second, learners should understand the difference between laws and theories. The former is about clarifying relationships between concepts and phenomena. The latter is about providing explanations.

Third, learners should understand that scientific knowledge can depend on human creativity and imagination. Even though it relies on observation of the natural world, provision and formation of explanations involve elements of invention and creation (Lederman, 2007).

Fourth, learners should recognize that scientific knowledge is subjective. Scientists who approach, discover, and construct new knowledge are likely to be influenced by their experience, beliefs, previous knowledge, personality, social institutions, and culture. All these factors affect the way scientists approach a problem, state hypothesis, plan observations, conduct experiments, and form explanations.

Fifth, it is important to understand that science is a human enterprise. This is linked with the points on imagination and creativity as well as subjectivity. Due to that, science focus, process, and knowledge are highly likely to be influenced by contemporary social, moral, religious, political, and economic factors. It is extremely unlikely for scientific research to focus on topics that are thought to be inappropriate by the wider community or religion (Lederman, 2007).

Sixth, knowledge of science is never absolute or concrete. Laws, theories, and scientific findings are always possible to change if new evidence comes to light. This point is relevant to the influences of science from the cultural, economic, social, and political aspects, which influence research and science discourse and may, therefore, lead to these data that will bring on modifications in the accepted scientific findings, theories, laws, and knowledge.

Finally, it is important to point out that the NOS is not synonymous to scientific inquiry. The latter includes a set of planned activities of observation, hypothesis, data collection, experimentation, analysis, and drawing conclusions. This is, of course, an important aspect of the NOS, but it is not the same. Inquiry is better described as a cyclical process involving different kinds of scientific activities.

Generally, when it comes to scientific knowledge and process, the basic points to focus are the fact that it is subjective, subject to change, empirically-based, and influenced by human activities and social and cultural matters (Lederman, 2007).

More specifically, according to the Next Generation of Science Standards report, teaching science should emphasize on the NOS by focusing on eight basic points-standards. These are: 1) investigations of science various methods, 2)scientific knowledge relies on empirical evidence, 3)scientific knowledge may be revised if new evidence comes to light, 4) natural phenomena are explained by scientific models, laws, mechanisms, and theories explain natural phenomena, 5) science is a cognitive system, 6)scientific knowledge assumes that there is order and consistency in natural systems, 7)science reflects human endeavour, and 8) science points out questions about the natural and material world (Hanuscin et al., 2011; NGSS, 2013). 


\section{NOS Teaching Implementation}

There have been various practices described by researchers and theorists about how educators can teach NOS. Challenges to that task however, have also been identified and described (Abd-El-Khalick et al., 1998). This can be linked to various factors. Textbooks and teaching packages generally seem to have an important role in that point (Irez, 2009).

\subsection{Recommended practices}

The science curriculum is known to be a major influence on science teaching and its effectiveness in many countries. Science teaching textbooks and teaching packages are expected to follow it. These packages are expected to assist the educators in achieving their goals in teaching science as with any other subject. Therefore, it is important for teachers to have the appropriately designed textbook and teaching package in order to work effectively. With regards to the NOS, if it is to be involved in science teaching and for the learners to understand it, there should be adequate focus on its' dimensions and requirements. Teaching packages and textbooks that treat science only as a core knowledge matter, i.e., focus on inquiry and project-based learning in a segmental way, are unlikely to be helpful for teachers. The practices that are recommended by research to be effective for teaching the NOS need to be involved in the curricula, the syllabi, and the teaching packages or textbooks, so that the teachers will be granted more opportunities to work in that direction as expected (Cibik, 2016).

However, Hind et al. (2001) claimed that even with the appropriate curriculum, the NOS teaching might not work effectively. One reason for that is the limited availability of resources and material that assist teachers in that direction. On account of this, these material and practices should focus on learners' understanding and help them overcome and reject any misconceptions they may hold with regard to the NOS and scientific epistemology. The focus on learners' understanding on epistemology from the teaching material focuses on three tendencies or dimensions. The first is about the purpose of scientific epistemology. The second is about the nature and mission of theoretical explanations in science. The third is about the quality of scientific data.

Any teaching material that aims to teach the NOS should take these points into consideration. It should involve activities and tasks that help learners understand the points (Abd-El-Khalick et al., 1998; Hanuscin et al., 2011; Cibik, 2016).

With regard to misconceptions and instructions on the purpose and traits of epistemology, the focus of teaching should be science as a methodological process. Standards that relate to this tendency are those that focus on scientific investigation and on the fact that it uses a variety of methods and aims to form laws and theories, and that science investigation is linked to identifying research questions about the natural world. Learners should understand that science process and investigation aim to discover or construct new knowledge and in 
doing so, hypothesis, experimentation, justification, and revision are required (Hanuscin et al., 2011; NGSS, 2013).

In order to treat misconceptions around the nature of theory and theoretical explanation, the focus of teaching should be on their need and importance, as the oversimplification of the relationship between theory and data might bring on challenges. The standards that relate to this topic are those that focus on the fact that science is a system to explain the natural world and that science is a human endeavour and it assumes order within the natural systems. Therefore, learners need to understand or articulate the role of models and theories in relation to interpreting data. In other words, they need to understand how they are constructed and for what reason.

The misconceptions about the quality and analysis of scientific data, are dealt with when the focus of teaching should be on their significance for science inquiry, the way they are collected, and the way scientists and researchers work with them. Accuracy and evaluation should also be pointed. The standards that relate to this trend are linked to the fact that scientific knowledge is based on empirical evidence, and it is open to revision in the light of new evidence. Hence, learners need to understand that the data have to be collected in order to lead to the construction of new knowledge. For that purpose, they must be accurate and directly related to concepts and phenomena that are being investigated (Hanuscin et al., 2011; NGSS, 2013).

Bearing in mind the above point, the NOS teaching is suggested to involve a set of worksheets and a portfolio. In other words, it seems to be not easy to convert guidelines to practices. Abd-El-Khalick et al. (1998) as well as Cibik (2016) supported that active learners' engagement in activities involving scientific inquiry and investigation is necessary. Educators should design and implement these activities while focusing on goals that are relevant to the NOS.

These will include sets of tasks that will help learners understand the points of each dimension. There should be tasks that help learners understand the process of science investigation and its importance to construct knowledge. These may be tasks of explaining, forming a hypothesis, justifying an experiment, designing experiments, and describing the importance of the way new knowledge constructed. These tasks familiarize learners with epistemology.

Simultaneously, there should be tasks that help learners understand the nature of theory and explanation. Such tasks may focus on why the models are used generally. Others may focus on why the theory is important, either generally or specifically in certain units. These familiarize learners with characteristics of theory.

Lastly, there should also be tasks that help learners understand the role of data. There may be tasks describing how, thanks to new data, scientific knowledge has changed. Perhaps, emphasis on the history of science might help in that case. Others may focus on evaluating the data about their relevance, accuracy, and necessity.

These tasks may be in worksheets that focus totally on the NOS. Furthermore, they may exist in worksheets that emphasize on individual topics. For example, 
there may be worksheets emphasizing on mechanics or photosynthesis, which may also include individual tasks about the NOS. In any case, it is recommended to assemble a portfolio of all these tasks and progressively observe how learners' knowledge about the NOS progresses (Abd-El-Khalick et al., 1998; Hanuscin et al., 2011; NGSS, 2013; Cibik, 2016).

\subsection{Challenges}

The NOS teaching is, therefore, important, and the literature has suggested guidelines for implementation. However, there are basic challenges that arise in implementing these NOS teaching. A basic challenge is the designing of the appropriate practices to assist the educator.

Another basic challenge is the evaluation of these actions and teaching interventions. As learning the NOS is about processes, skills, and attitudes, apart from content knowledge, the most appropriate technique for evaluation is based on continuous discourse and discussion with learners, as well as observations. These should pay attention to the way learners hypothesize, investigate, exchange ideas, and construct knowledge. Formal processes of evaluation, such as written exams, might help but is not always considered necessary (Hanuscin et al., 2011).

Abd-El-Khalick et al., (1998) claim that teaching the NOS has not been systematically included in science teaching across many countries as concluded by research. Perhaps, the most important reason for that is the emphasis paid usually in concepts and phenomena, accompanied by the lack of the appropriate focus on behalf of Curricula and Syllabi. Besides that, although there have been significant efforts to implement inquiry-based science teaching, which can serve as foundation to teaching the NOS, literature claims that challenges, in that aspect, still remain. This brings on more barriers to the NOS teaching. Educators can respond in this situation by forming the appropriate teaching goals triggered by their own initiative. It is important for them to have the appropriate flexibility or the appropriate curriculum (Lederman et al., 2002; Akerson \& Hanuscin, 2007; Manz \& Suarez, 2018; Masters \& Park Rogers, 2018).

The effectiveness of teaching the NOS is interrelated in literature and research with the existence of appropriate teaching material. It is common for research projects to point out that challenges in teaching the NOS for teachers arise due to the inappropriateness of textbooks, either by the omission of its dimensions or with the promotion of misconceptions about it (Akerson \& Hanuscin, 2007; Hanuscin et al., 2011; Cibik, 2016). Even though significant emphasis is paid to teachers' understanding of the NOS and the necessity for its implementation in their teaching, lack of the appropriate material is highly likely to prevent them from doing so (Cibik, 2016).

\subsection{The role of textbooks}

Textbooks are designed for educational purposes. However, they are more than just a means of teaching. They reflect, directly or indirectly, a series of cultural beliefs about education and teaching, in general, and specifically, about the 
subject taught. Textbooks provide teachers with concrete lesson plans and worksheets, which are planned according to the accepted principles concerning learning and assessment. This way, they are thought to provide or assist in the implementation of literature findings and curriculum standards, often accompanied by the teachers' guide. Science textbooks, for example, are an outcome of the wider beliefs about how science should be taught (Pingel, 2010).

The effectiveness of the teaching intervention toward science learning and understanding is relevant to the approaches, means, and materials that teachers use in their work. Science textbooks are justified in research to have a significant role in science learning and learners' progress, which affects learners' approach to science (Irez, 2009). The textbook is sometimes treated by learners and teachers as the most important source of knowledge in that area. Therefore, it is important for textbooks to follow and reflect the guidelines and goals set by the National Curricula along with the main points of literature around science education (Khine, 2013).

Tobin \& McRobbie (1997) as well as Irez, (2009) conclude that science textbooks rarely emphasize the aspects around the NOS. Instead, they treat science as a sum of content knowledge and sum of information, concepts, vocabulary, or phenomena to be understood and memorized. These are the points of science lesson where examinations, assessment, and tests tend to be emphasized. Effective science teachers are considered to be those able to assist learners to construct this sum of knowledge and assist them to achieve efficient performance in this examination. This leaves little room for teachers to focus on the sessions and their work on topics such as the NOS

Chiappetta et al. (1993), after researching and examining five textbooks used in science classes, concluded that most of these emphasized on aspects such as science mostly as inquiry and body of knowledge. Science as a way of thought and the interaction of science with the society were aspects that gained less importance. Similar conclusions were drawn by the research of Gibbs and Lawson (1992) on 22 science textbooks. More recently, Phillips and Chiappetta (2007), through a research of 12 science textbooks, were lead to the finding that even though the NOS gains a higher than before percentage of attention, still the comparatively greatest part of the book treats science solely as a body of knowledge. Irez (2009) as well as Chairsi and Thathong (2014) stressed the importance of science textbooks to be reconstructed in order to help teachers understand and better deliver the knowledge about the NOS.

These researchers mostly used quantitative approaches in their work. They focused on measuring the coverage and the emphasis of the textbooks on the dimensions, standards, and basic points of the NOS. In other words, the researchers calculate the percentage of the texts, activities, and tasks that focus on epistemology, the explanatory nature and data issues. Even though each research group has adopted different categorization of the points of the NOS, these three were the basic dimensions examined in all the research projects (Lederman, 2007). Irez (2009) not only supported the above argument but also claimed that perhaps a qualitative approach toward textbook evaluation could also provide significant insights for such research. The reason is the basic 
characteristics of the NOS, along with the recommendations and suggestions of literature about the appropriate NOS teaching interventions.

\section{The design of the research}

The design of the research, should take into consideration the context where it takes place, the relevant literature and theory, in order to draw the appropriate research questions. These will be a guide to the suitable methodology (Cohen et al, 2013).

\subsection{Science in the Greek Primary School}

This research was planned keeping all the above in mind. The research aimed to investigate the possibility of promoting the NOS in the Greek Elementary School. In doing so, the research wants to examine the conditions of primary science teaching in Greece, keeping in mind the aims and the materials used by the teachers. This material needs to be benchmarked across the criteria that research identifies as crucial and important in promoting the NOS and rejecting the relevant misconceptions. In other words, it needs to be examined whether the material used satisfies the dimensions of epistemology, theoretical explanation, and quality of data, in combination with the relevant standards (Hanuscin et al., 2011; NGSS, 2013).

Science is a core subject in the Greek Primary School Curriculum, just as it is the case in many countries. The Greek Primary School addresses children from the ages of 6 to 12 years old and includes six consecutive grades. During the first four grades, pupils learn science within the subject of Environmental Study, which is an integrating subject encompassing units on topics of science, geography, and social issues. During the last two grades, though these subjects become independent, science is taught as an autonomous subject for three weekly sessions. The topics included in the science subject are matter structure and states, energy, plants, animals, mechanics, electromagnetism, anatomy of the human body, and sound and light.

As with most subjects in the Greek Primary School, the teachers are expected to use teaching packages distributed free of charge in schools. This includes the pupils' book and workbook, which are distributed to pupils and teachers, and the teachers' book, which is distributed only to teachers. Apart from that, a set of recommended software is suggested to be used. In science, particularly, the sessions are usually expected to be implemented with the help of the workbook, which includes experimental activities and assists learners in knowledge construction (MINEDU, 2011; OECD, 2017).

\subsection{Research on textbooks}

This research should focus on identifying whether primary science teaching package of the Greek Elementary School fulfils the conditions of teaching the NOS effectively. Analysis of science of textbooks in that respect is based on identifying the number and content of tasks that focus on the dimensions of the 
NOS (Gibbs \& Lawson, 1992; Chiappetta et al., 1993; Phillips \& Chiappetta, 2007; Irez, 2009; Chairsi \& Thathong, 2014)

For that scope, there is a need for textbook content analysis, which Hsieh and Shannon (2005) state that it serves as a method for systemic interpretation of data deriving from texts. This interpretation follows a process of classifying the data according to codes and criteria and aims to identify themes or patterns. This process pays attention to contextual meaning. Three different types of qualitative content analysis have been described. These differ mostly on its aims, the way it is planned, and its implementation.

The first is called "conventional content analysis." In this approach, at the beginning, the texts are read, without making remarks. This initial reading is followed by an attentive word-by-word reading. During this, the keywords and concepts are pointed out. Then, researchers code these words or concepts. The codes are then categorized into clusters. After that, relationships between codes or clusters are identified and developed. This approach is useful in cases where the phenomenon under study has not been researched extensively. In such cases, since there is little literature around it, researchers cannot have pre-determined codes (Hsieh \& Shannon, 2005).

The second one is known as "directed content analysis." Contrary to the previous approach, this can be implemented to validate or extend an existing theoretical framework. Researchers benefit from existing theory to form research questions, state hypotheses or assertions, name codes, and identify variables that are relevant to their project. Then, the texts are analyzed. The analysis includes thorough reading and pointing out which words, phrases, and text parts can be included in the pre-determined codes. It is likely for new codes to be defined. By linking codes between them and with research questions, the existing theory can be justified or unjustified in a new context.

The third is called the "summative content analysis." A research project following this approach tends to start by identifying exact words or phrases, which are relevant to the topic under study, instead of codes. These are counted. An analysis of the meaning and its interpretation lead to significant conclusions that could reflect patterns between words and perceptions. The main advantage of this approach is that it gives insights into the words being used and the meanings attributed to them. The main disadvantage is the credibility factor, as the interpretation in some cases relies on the researchers' point of view (Hsieh \& Shannon, 2005).

In the light of the scope of this research, the most appropriate approach is the directed content analysis. Since there is already a disseminated theory about practices that promote learning the NOS and even more specifically that which can be learned in secondary science textbooks, it is possible to use this theory and literature as a source for codes and nodes. Textbook analysis can then be based on these codes (Hsieh \& Shannon, 2005; MINEDU, 2011; NGSS, 2013). 


\subsection{Implementation of the approach}

Zhang and Wildemuth (2016) drew an 8-step thorough process to implement directed content analysis. This is a flexible process design, which can be adapted to the needs of each research project.

The first step is to prepare the data. In this case, the data are the teaching packages of elementary science in the Greek school, which involves three books. The teachers' book consists lesson plans designed for the teacher to implement. Then, there is the pupils' book, which contains texts. Finally, there is the workbook, which includes the worksheets, with the activities that the learners need to be involved in. In most subjects, pupils usually work with the pupils' book, while the workbook is expected to involve application of tasks. However, science is an exception (MINEDU, 2011). For the scope of this research, all these books need to be involved and analyzed (Cohen et al., 2013).

The second step involves definitions of the contents for analysis. In this step, it is necessary to clarify what text or resource will be used and what kind of data from the text are needed for the analysis. In this research, bearing in mind the scope and design of the science subject, it is important to check texts and activities of the workbook, along with the texts of the pupils' and teachers' book. Points, texts, and tasks that emphasize on the NOS should be identified and noted.

The third step involves identifying and deciding the codes. The codes that can be defined for this study relate to the standards about teaching the NOS. Each standard criterion can be represented by a specific code (Hanuscin et al., 2011; NGSS, 2013). The codes can be then categorized to nodes, which can reflect the basic dimensions of the tendencies described by Hind et al. (2001). Hence, there should be a category about "epistemology", which would include the codes "methodology", "Theory focus" and "Question identification." There should be a category about "Science Explanation", which will include the codes, "human endeavour", "explanation system", and "natural order." Finally, there should be a category about "Data Quality", which would include the nodes "empirical evidence", and "knowledge revision" (Cohen et al., 2013).

It is on the fourth step that actual research starts being implemented. This step is a pilot form of study, as it involves testing the coding planned in a sample of the text. This gives opportunity to validate the effectiveness of coding and the possibility to provide accurate, concrete, valuable data, findings, and conclusions. If difficulties and problems emerge, then coding needs to be revised and re-checked. If coding seems to be leading to desired conclusions and helps the accomplishment of the research, then the next step may begin, even though it is recommended that the possibility of revision should never be considered impossible.

The fifth step includes coding the whole text, which is essentially the data analysis process. By identifying the frequency from which the codes emerge, it is possible to answer whether the elementary science teaching package promotes the NOS. Even though revision of codes and nodes should have happened during the fourth step, it is still possible to occur during the fifth as well as the sixth step, which includes checking the consistency of codes and the possibility 
they offer to answer the basic questions of the research. This will lead to the seventh step, which includes drawing the final conclusions of coding and research and finally the eighth, which includes reporting the findings (Hind et al., 2011).

\subsection{Research Questions}

In order to answer whether the teaching package of the Greek Elementary School promotes teaching the NOS, it is necessary to identify whether it promotes the three basic dimensions: scientific epistemology, explanatory nature, and data accuracy. Research has pointed out that for that goal to be achieved, textbooks and teaching packages need to emphasize on the process of inquiry and the rational of each step of it as part of the scientific work and the NOS generally (Akerson \& Hanuscin 2007; Hanuscin et al., 2011; Cibik, 2016). This way, the teaching interventions will satisfy the eight basic standards that the NOS calls for (Hanuscin et al., 2011; NGSS, 2013). Having this piece of literature in mind, as basis and direction (Hsieh \& Shannon, 2005), the content analysis of the textbooks will focus on answering the following three basic questions:

1. Are basic characteristics of scientific epistemology pointed out in the teaching package?

2. Does the teaching package focus on the explanatory nature of science?

3. Is the quality and concept of data approached in the teaching package?

The first question addresses the standards of scientific investigation. This refers to the fact that it uses a variety of methods, aims to form laws and theories, and that science investigation is linked to identifying research questions about the natural world. The codes relevant are "scientific method," "question identification," and "theory focus" (NGSS, 2013). Emphasis on these provides grounds for learners to reject misconceptions around the NOS and inquiry, as well as confusion between laws and theories (Lederman, 2007).

The second question addresses the standards on scientific explanation. These refer to the fact that science is a system to explain the natural world and that it is a human endeavour and assumes order within natural systems. The codes relevant are "human endeavour," "explanation system," and "natural order" (NGSS, 2013). Emphasis on these helps learners understand the role of human effort in scientific explanation and knowledge construction and reject relevant misconceptions (Lederman, 2007).

The third research question addresses the standards on data. These refer to the fact that scientific knowledge is based on empirical evidence, and it is open to revision in the light of new evidence. The relevant codes are "data quality," "empirical evidence," and "knowledge revision" (NGSS, 2013). By emphasizing on these, it is possible for learners to tackle misconceptions around scientific knowledge and the way it is formed or changed (Lederman, 2007).

These three questions will be answered based on the codes and nodes that have been identified by a thorough examination of the teachers' book, the pupils' 
book, and the workbook, which composes the teaching package of science (MINEDU, 2011). The analysis will be benchmarked with the codes of the curriculum, so that it will be examined whether there is the desired consistency in what concerns the NOS teaching, which, according to research, is missing usually (Tobin \& McRobbie, 1997; Abd-El-Khalick et al., 1998; Lederman et al., 2002; Chiappetta, 2007; Lederman, 2007; Irez, 2009).

\section{Findings}

As shown by the findings, there are aspects of NOS promoted in the Greek textbooks (MINEDU, 2011), however there are points to consider (Abd-ElKhalick et al., 1998; Irez, 2009).

\subsection{First research question "Are basic characteristics of scientific epistemology pointed out in the teaching package?"}

With regard to the first research question, on the teaching package, there are several emerging codes concerning the epistemological dimension of the NOS and its characteristics, as demonstrated in figure 1.

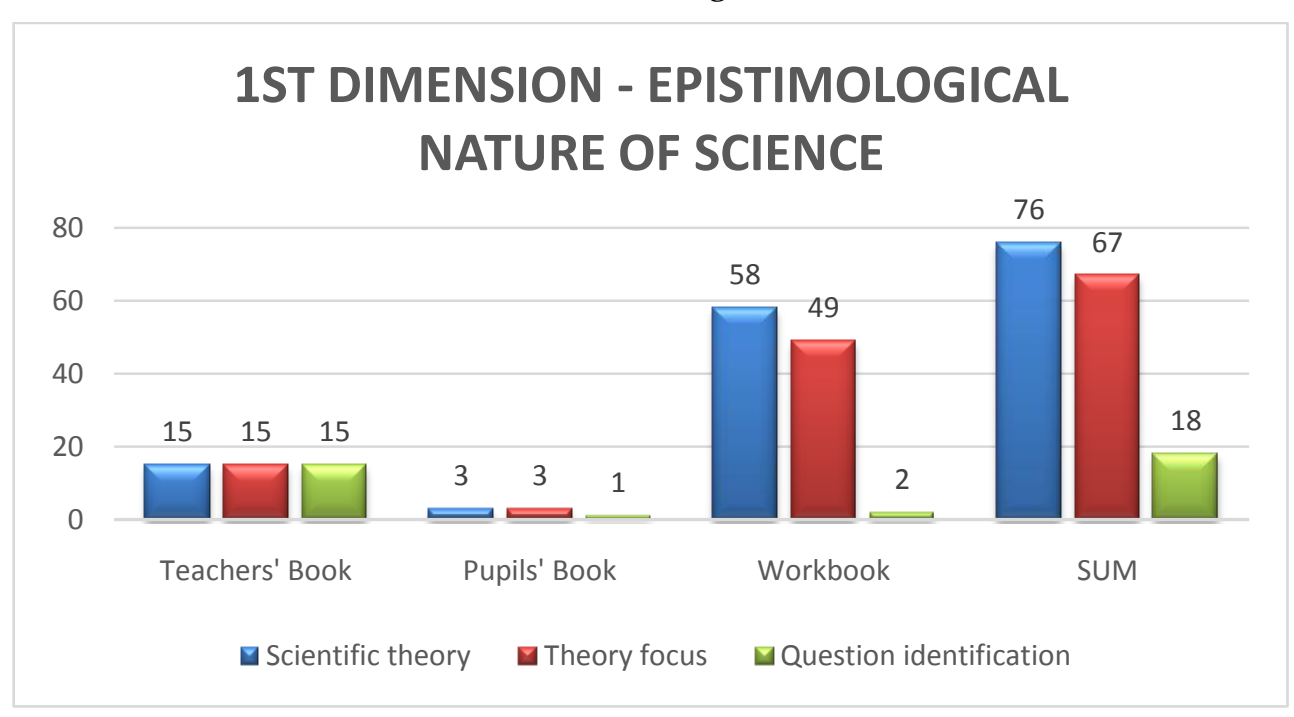

Figure 1: Nodes on the first research question.

In the teachers' book, the codes "scientific method," "question identification," and "theory focus" are identified in points, which were mostly emphasizing the process of scientific inquiry. This is mostly apparent at the beginning, where there is a general introduction about the subject of science and its mission.

In the pupils' book, the codes "scientific method" and "theory focus" were only identified a limited number of times. The code about question identification was noted only once. As with the teachers' book, the codes were found mostly at the beginning, where the process of scientific inquiry and its importance were explained. 
In the workbook, which is recommended to be the main teaching book for the sessions, the codes "scientific method" and "theory focus" were identified plenty of times. Each worksheet included activities that addressed these aspects of inquiry. However, the code about "Question identification:" was barely noted. The worksheets were designed in such a way that the learners would implement scientific method and conclude to a theory. There was no emphasis on identifying questions though.

The relevant set standards for using methods, theory importance, and pointingout questions are overall stressed (NGSS, 2013). This might stimulate learners to reject misconceptions of confusing laws with theories and the NOS with inquiry (Lederman, 2007).

These findings show that overall, in the teaching package, there is emphasis on the aspect of epistemology and inquiry. However, this is rather restricted in some cases. Even though there is adequate mentioning on the process of scientific method and the importance to construct theory, there is limited focus on question identifying, which is an important part of science inquiry. Such findings are compatible with the main conclusions of similar research projects (Tobin \& McRobbie, 1997; Abd-El-Khalick et al., 1998; Chiappetta, 2007; Irez, 2009).

\subsection{Second research question "Does the teaching package focus on the explanatory nature of science?"}

With regard to the second research question, just as with the first, the codes relevant to the codes about science explanation emerge in several parts of the teaching package, as it can be seen in figure 2 .

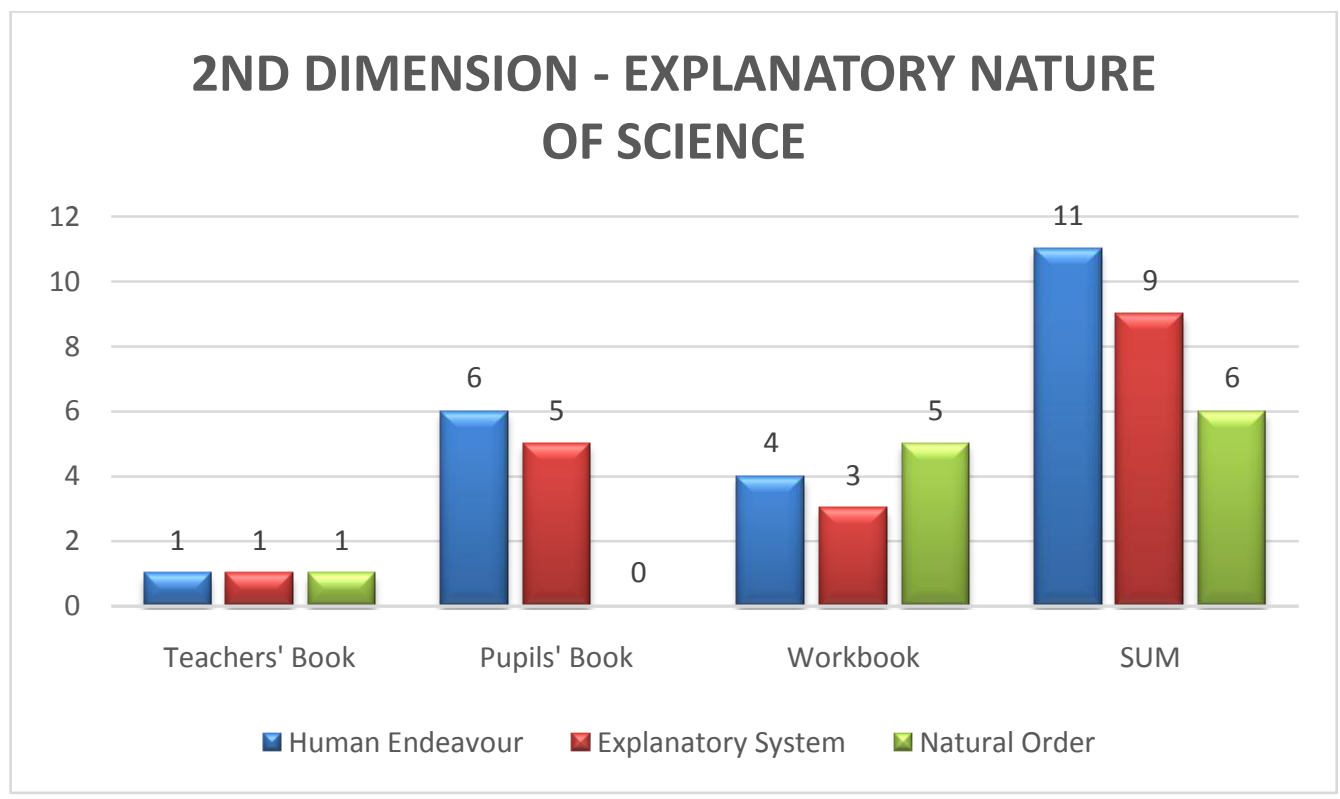

Figure 2: Nodes on the first research question. 
First, in the teachers' book, there has been a single note of the codes "human endeavour," "explanation system," and "natural order." This applied mostly in the initial introductory part, which focuses on the general mission of scientific subject, on guiding principles of science teaching and the NOS generally.

In the pupils' book, there have been several times, where the codes "human endeavour" and "explanation system" were noted. Again, this was in the introductory chapter where there was a brief description of how scientific work is done and how knowledge is constructed. Throughout the rest of the text, there have been points that referred to historical experiments where these nodes were noted. However, there was no point where "natural order" was pointed. This happens as there is a reference in the experiments and their contribution to scientific knowledge, but there was no emphasis on the scientific approach on the systems.

Similar is the picture in the workbook. In the introductory part, where there is detail about how learners should approach and work with worksheets, the codes "human endeavour" and "explanation system" emerged seven times. However, the natural "order code" was found in no case.

The standards concerning science as a cognitive system, human endeavour, and natural order does not seem to be adequately stressed. This provides little opportunities for teachers to assist learners in rejecting misconceptions that have to do with the role of observation and explanation and the role of human activity in science and knowledge (Lederman, 2007). Therefore, the explanatory NOS is promoted only to an extent (Tobin \& McRobbie, 1997; Lederman et al., 2002; Chiappetta, 2007; Irez, 2009).

\subsection{Third research question "Is the quality and concept of data approached in the teaching package?"}

With regard to the third research question, the results are similar, as the codes relevant to data quality and accuracy were rather limited. However, these codes were not frequently observed in the teaching package, as it can be seen in figure 3. 


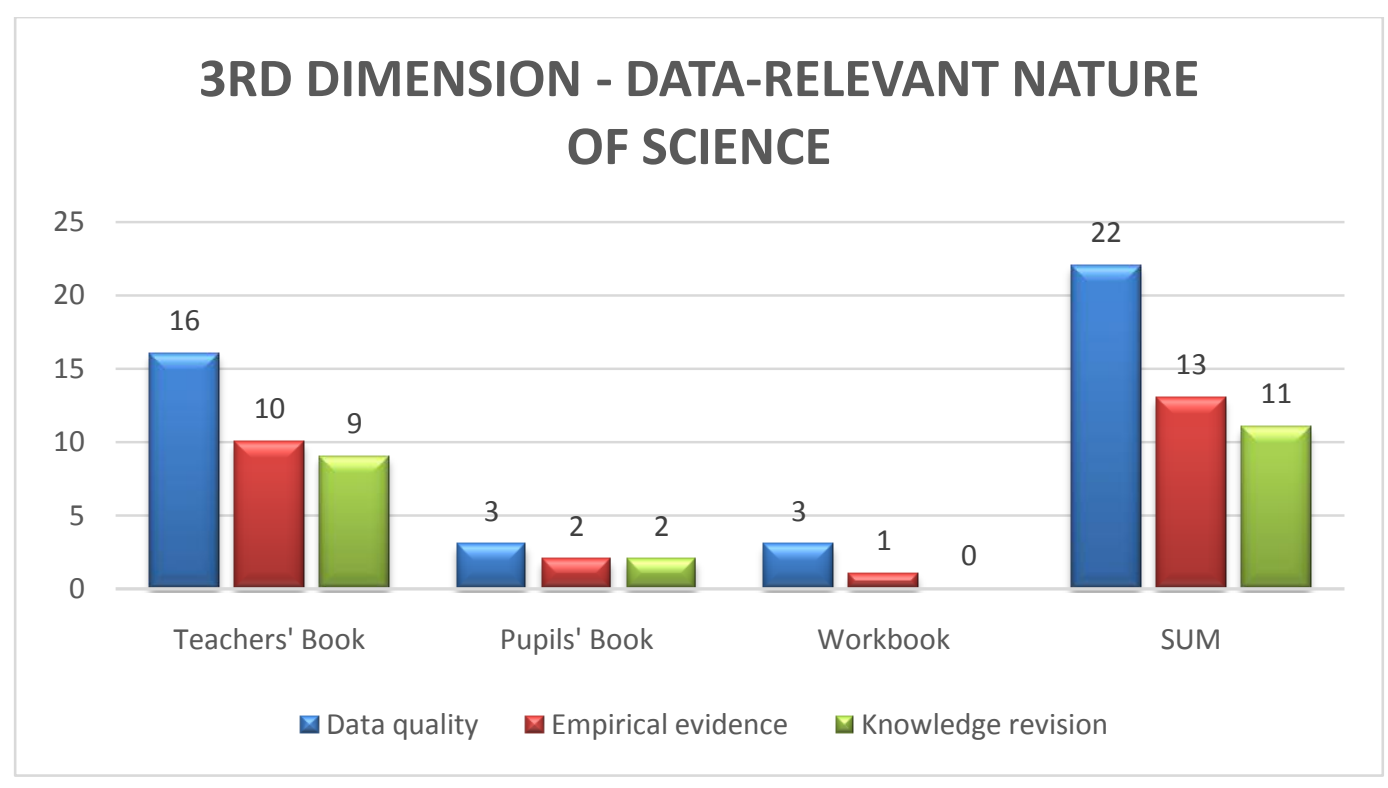

Figure 3: Nodes on the third research question.

In the teachers' book, these codes emerge rather frequently. As with previous research questions, in the introductory part, it is clearly stated that scientific knowledge derivers from data and can be revised. Furthermore, there is indirect mentioning on the necessity to have accurate data in order to draw the appropriate conclusions to construct scientific knowledge.

In the pupils' book, these codes again emerge in the beginning, but only a limited number of times, when explaining how scientific knowledge is constructed. During the main chapters of the book, where the science topics are analyzed, there is no emphasis on the issues about the changing knowledge and the need for data. There is only emphasis on the content knowledge, concepts, phenomena, and information generally.

In the workbook, as with pupils' book, the codes emerge again a limited number of times in the beginning. In the individual worksheets, learners are expected to work by implementing the simple experiments already described. However, in the descriptions and instructions of these activities, the need to have accurate data is not mentioned. Moreover, it is not mentioned that the knowledge constructed, the so-called "conclusion" could change in the light of new data.

These findings show little emphasis on the standards about the need for evidence and data and the possibility to revise knowledge in the light of new evidence (NGSS, 2013). Misconceptions that relate to the subjectivity of knowledge are not thoroughly negotiated in the teaching package (Lederman, 2007). In short, in what concerns the knowledge accuracy dimension, even though there is an initial acknowledgment, in implementation, there seems to be little emphasis (Tobin \& McRobbie, 1997; Abd-El-Khalick et al., 1998; Chiappetta, 2007; Lederman, 2007; Irez, 2009). 


\section{Conclusions}

The point of this research was to identify whether the teaching package of elementary education in Greece pays emphasis on teaching NOS. Including the NOS in science teaching is recognized by research to contribute to an in-depth understanding of the science subject, and it contributes a lot to the effective development of scientific literacy from learners (OECD, 2006; Roblin et al, 2017). Teaching the NOS needs to follow certain practices and satisfy eight basic guidelines, known as "standards," which address to epistemology, explanatory, and data aspects of science, as it should be involved in teaching. These emphasize on the dimensions of science as a system to explain the natural world, the inquiry-based epistemology, and scientific data and knowledge characteristics (NGSS, 2013; Manz \& Suarez, 2018; Masters \& Park Rogers, 2018). The role of textbooks in that direction has been described as crucial in research. In fact, textbooks, usually present science mostly as a body of knowledge and pay little attention to other important dimensions of the NOS (Irez, 2009).

In public elementary schools in Greece, according to the relevant legislation, science is taught in the final two grades. The teaching package distributed by the Ministry of Education includes the teachers' book, the pupils' book and the workbook (MINEDU, 2011). In order to identify whether this package actually promotes the NOS, it was necessary to see if the three basic dimensions are involved in it. The directed content analysis approach was followed for this purpose (Hsieh \& Shannon, 2005).

The results of this analysis show that although there has been emphasis in the introductory parts of the books about the NOS, throughout the rest of the books, in the individual chapters and worksheets that learners are expected to work, there seems to be little or no emphasis. This finding is compatible with the general research outcomes (Tobin \& McRobbie, 1997; Abd-El-Khalick et al., 1998; Lederman et al., 2002; Chiappetta, 2007; Lederman, 2007; Irez, 2009).

At that finishing stage, it is important to stress the limitations of the particular study. Before generalizing the conclusions, it should be mentioned that it focused on the teaching package of two grades. At a later stage, it might be worth investigating the opinions of teachers around the implementation of the NOS teaching (Cohen et al., 2013).

\section{References}

Abd-El-Khalick, F., Bell, R. L., \& Lederman, N. G. (1998). The nature of science and instructional practice: Making the unnatural natural. Science Education, 82(4), 417-436. doi:10.1002/(SICI)1098-237X(199807)82:4<417::AID-SCE1>3.0.CO;2-E

Akerson, V. L., \& Hanuscin, D. L. (2007). Teaching nature of science through inquiry: Results of a 3- year professional development program. Journal of Research in Science Teaching, 44(5). 653-680. doi:10.1002/tea.20159

Bell, R.L. (2008). Teaching the nature of science through process skills: Activities for grades 3-8. New York: Allyn \& Bacon/Longman. doi: 10.18130/v35r8g

Chaisri, A., \& Thathong, K. (2014). The nature of science represented in Thai biology textbooks under the topic of evolution. Procedia-Social and Behavioral Sciences, 116. 621-626. doi: 10.1016/j.sbspro.2014.01.268 
Chiappetta, E. L., Sethna, G. H., \& Fillman, D. A. (1993). Do middle school life science textbooks provide a balance of scientific literacy themes? Journal of Research in Science Teaching, 30(7). 787-797. doi: 10.1002/tea.3660300714

Cibik, A.S. (2016). The effect of project-based history and nature of science practices on the change of nature of scientific knowledge. International Journal of Environmental and Science Education, 11(4). 453-472. doi: 10.12973/ijese.2016.331a

Clough, M. P. (2007). Teaching the nature of science to secondary and post-secondary students: Questions rather than tenets. In The pantaneto forum (Vol. 25, pp. 31-40). Retrieved from http://www.pantaneto.co.uk/issue25/clough.htm

Cohen, L., Manion, L., \& Morrison, K. (2013). Research methods in education. $7^{\text {th }}$ ed. London: Routledge. doi: 10.4324/9780203720967

Driver, R., Leach, J., Millar, R., \& Scott, P. (1996). Young people's images of science. Philadelphia: Open University Press. doi: 10.1080/03057268308559904

Gibbs, A., \& Lawson, A. E. (1992). The nature of scientific thinking as reflected by the work of biologists \& by biology textbooks. The American Biology Teacher, 54(3). 137-152. Doi: $10.2307 / 4449435$

Hanuscin, D. L., Lee, M. H., \& Akerson, V. L. (2011). Elementary teachers' pedagogical content knowledge for teaching the nature of science. Science Education, 95(1). 145-167. doi:10.1002/sce.20404

Hind A., Leach J., \& Ryder J. (2001). Teaching about the nature of scientific knowledge and investigation on AS/A level science courses, technical report, University of Leeds, Retrieved from http://www.nuffieldfoundation.org/aboutscience/index.shtml

Hsieh, H. F., \& Shannon, S. E. (2005). Three approaches to qualitative content analysis. Qualitative Health Research, 15(9). 1277-1288. doi: 10.1177/1049732305276687

Irez, S. (2009). Nature of science as depicted in Turkish biology textbooks. Science Education, 93(3). 422-447. doi: 10.1002/sce.20305

Khine, M. S. (Ed.). (2013). Critical analysis of science textbooks: Evaluating instructional effectiveness. Netherlands: Springer Science \& Business Media. doi: 10.1007/97894-007-4168-3_15

Lederman, N. G., Abd- El- Khalick, F., Bell, R. L. and Schwartz, R. S. (2002), Views of nature of science questionnaire: Toward valid and meaningful assessment of learners' conceptions of nature of science. Journal of Research in Science Teaching, 39(6), 497-521. doi:10.1002/tea.10034

Lederman, N.G. (2007). Nature of science: Past, present, and future. In S.K. Abell, \& N.G. Lederman, (Editors), Handbook of research in science education (pp 831-879). Mahwah, New Jersey: Lawrence Erlbaum Publishers

Manz, E. and Suárez, E. (2018). Supporting teachers to negotiate uncertainty for science, students, and teaching. Science Education, 102(4), pp.771-795. doi: $10.1002 /$ sce. 21343

Masters, H. L. \& Park Rogers, M. A., (2018) Examining early elementary teachers' pedagogical content knowledge for teaching scientific explanations. Journal of Science Teacher Education, 29(3). 223-242. Doi: 10.1007/0-306-47217-1_7

MINEDU (2011). GREEK MINISTRY OF EDUCATION AND RELIGIOUS AFFAIRS. Mathematics and Science Curriculum for Primary and Secondary Education. Athens: Pedagogical Institute.

NGSS Lead States (2013). Next generation science standards: For states, by states. Washington, DC: The National Academies Press. doi: 10.17226/18290

OECD, (2006). Assessing Scientific, Reading and Mathematical Literacy. OECD Publishing. Paris. doi:10.1787/9789264026407-en 
OECD, (2017). Education for a bright future in Greece. Reviews of National Policies for Education. OECD Publishing. Paris. Retrieved from http://dx.doi.org/10.1787/9789264298750-en. doi: 10.1787/9789264298750-en

Pingel, F. (2010). UNESCO guidebook on textbook research and textbook revision. Paris: UNESCO.

Phillips, M. C., \& Chiappetta, E. L. (2007). Do middle school science textbooks present a balanced view of the nature of science? Paper presented at the annual meeting of National Association for Research in Science Teaching, New Orleans, LA.

Roblin, N. P., Schunn, C., \& Mckenney, S. (2017). What are critical features of science curriculum materials that impact student and teacher outcomes? Science Education, 102(2). 260-282. doi: 10.1002/sce.21328

Tobin, K., \& McRobbie, C. J. (1997). Beliefs about the nature of science and the enacted science curriculum. Science \& Education, 6(4). 355-371. doi: 10.1023/a:1008600132359

Zhang, Y., \& Wildemuth, B. M. (2016). Qualitative analysis of content. Applications of social research methods to questions in information and library science, 318. Retrieved from https://www.ischool.utexas.edu/ yanz/Content_analysis.pdf 